\title{
Methylglyoxal: Antimicrobial activity against blood culture isolates of Salmonella Typhi and other Gram negative rods
}

\author{
Raja Kamran Afzal' ${ }^{1}$, Fizza Khalid², \\ Abdul Hannan ${ }^{3}$, Syed Azhar Ahmed ${ }^{4}$
}

\begin{abstract}
Objectives: To evaluate the activity of Methylglyoxal against the blood culture isolates of Salmonella Typhi and various Gram negative rods and to compare the activity of Methylglyoxal against S. Typhi and other Gram negative rods.

Methods: It was an experimental study conducted at the Department of Microbiology, University of Health Sciences (UHS), Lahore-Pakistan in collaboration with the Department of Microbiology, CMH Lahore, from July 2011 to June 2012. Recent blood culture isolates of S. Typhi and other Gram negative rods were collected from different hospitals of Lahore and kept stored at $-80^{\circ} \mathrm{C}$. As per the latest CLSI guidelines, morphological, biochemical and serological identification was carried out and antimicrobial susceptibility was tested. A multi-point inoculator was used to carry out agar dilution for determination of MICs of MGO. Results were determined after compilation of data using latest SPSS version.

Results: $\mathrm{MIC}_{90}$ of $\mathrm{MGO}$ against the clinical isolates of $\mathrm{S}$. Typhi was $0.20 \mathrm{mg} / \mathrm{mL}(2.8 \mathrm{mM})$ and against Gram negative rods it was $0.21 \mathrm{mg} / \mathrm{mL}(3.0 \mathrm{mM})$. The $\mathrm{p}$-value of MICs of MGO against the isolates of $\mathrm{S}$. Typhi was 0.023 when compared with Gram negative rods ( $<<0.05$; statistically significant).

Conclusion: MGO has a scientifically proven in vitro antimicrobial activity against blood culture isolates of S. Typhi and various Gram negative rods.
\end{abstract}

KEYWORDS: Blood culture, Gram negative rods, Methylglyoxal, Salmonella Typhi.

How to cite this:

doi: https://doi.org/10.12669/pjms.35.4.807

Afzal RK, Khalid F, Hannan A, Ahmed SA. Methylglyoxal: Antimicrobial activity against blood culture isolates of Salmonella Typhi and other Gram negative rods. Pak J Med Sci. 2019;35(4):1110-1114. doi: https://doi.org/10.12669/pjms.35.4.807

This is an Open Access article distributed under the terms of the Creative Commons Attribution License (http://creativecommons.org/licenses/by/3.0), which permits unrestricted use, distribution, and reproduction in any medium, provided the original work is properly cited.

1. Dr. Raja Kamran Afzal, FCPS, PhD.

Department of Pathology,

Armed Forces Institute of Cardiology,

Rawalpindi, Pakistan.

2. Fizza Khalid,

3. Dr. Abdul Hannan, Dip Card, FRCPath.

4. Dr. Syed Azhar Ahmed, FRCPath, PhD.

Department of Pathology,

Baqai Medical University, Karachi, Pakistan.

2-3: Department of Pathology,

University of Health Sciences, Lahore, Pakistan.

Correspondence:

Dr. Raja Kamran Afzal, FCPS, PhD.

Assistant Professor,

Armed Forces Institute of Cardiology \&

National Institute of Heart Diseases,

Rawalpindi, Pakistan.

Email: rajakamranafzal1@gmail.com

* Received for Publication:

March 28, 2019

* $1^{\text {st }}$ Revision Received:

May 3, 2019

* $2^{\text {nd }}$ Revision Received: June 10, 2019

* Final Revision Received: * June 12, 2019

\section{INTRODUCTION}

Medical research is continuing towards administration of honey for systemic infections, particularly where conventional therapy is failing. On the basis of its prominent antibacterial activity, honey is being chosen by physicians naturally as an alternate antimicrobial compound. ${ }^{1}$ The 'beeorigin factors of honey are its increased osmolarity, reduced $\mathrm{pH}$ and $\mathrm{H}_{2} \mathrm{O}_{2}$ released by glucose oxidase. Second is methylglyoxal (MGO), which is the nonperoxide factor of 'plant-origin'. These are its main contributing antibacterial factors. ${ }^{2}$ With the help of chemiluminescence-HPLC, a portion of New Zealand manuka nectar has been isolated which shows antimicrobial activity in a non-peroxide way. ${ }^{3}$ As compared to the other flora of honeys, there is atleast 100 -folds higher concentration of

Pak J Med Sci July-August 2019 Vol. 35 No. $4 \quad$ www.pjms.org.pk 1110 
MGO in manuka honey (Leptospermum scoparium). By modifying the structure of target molecules, MGO plays a role in the pathogenesis of impaired diabetic wound healing. ${ }^{4}$ The conversion kinetics of dihydroxyacetone (DHA) to MGO were studied in mānuka and other honeys and it was found that MGO originates from a change in an abundantly present compound called DHA in the nectar of manuka flowers. ${ }^{5}$ The strength and impact of an antimicrobial agent in honey is dependent upon the concentration of MGO in it. Previously the power of manuka honey has been rated by the nectar producers as Unique Manuka Factor (UMF). Because of its potent antimicrobial properties, manuka honey having higher UMF is in high demand. ${ }^{6}$ Advanced glycation end products (AGEs) of protein and DNA give rise to a highly reactive precursor and a dicarbonyl compound called MGO. Newer experiences demonstrate that higher levels of MGO, the MGO derived AGEs (MGO-AGE) and hydroimidazolone-1 (MGO-H1), along with dysfunctioning framework of glyoxalase are connected to a few age-related medical issues including certain cardiovascular problems, diabetes, disorders of central nervous system and cancer. MGO has been demonstrated to act by developing AGEs and glutathione adducts in cytoplasm of the cells, including microscopic organisms. ${ }^{7}$ Recently, some antibiotics have also shown synergistic effects when used in the presence of MGO, e.g., with linezolid against $S$. aureus. ${ }^{8}$ It has also been proved lately that MGO is a potent in vitro antimicrobial agent against both planktonic and biofilm producing bacteria like $S$. aureus and $P$. aeruginosa, while being safe to the mucosal surface. ${ }^{9}$ The vast potential for usage and application of MGO as the non-preoxide part of medical grade honey within the medical field still remains unexplored.

Typhoid is still a major health issue causing mortality and morbidity in developing countries. About 11 to 21 million new patients globally and between 128,000 and 161,000 deaths due to typhoid occurperyear, asstated by World Health Organization lately. About $93 \%$ of these cases are reported from Asia. ${ }^{10}$ Reduced ciprofloxacin susceptibility and the emergence of multidrug resistance in S. Typhi have rendered conventionally used anti-typhoid drugs like ampicillin, chloramphenicol and co-trimoxazole ineffective for treatment. The real prospect to be faced is that untreatable typhoid fever is likely to emerge sooner or later. ${ }^{11}$ After fluoroquinolone and multidrug resistance, the rapidly spreading ceftriaxone resistance allover Pakistan is a big cause of concern for the public health and medical authorities, which has been classified as extensively drug resistant (XDR Typhoid). ${ }^{12}$ Consequently, efforts have to be made to evaluate new agents having potent antibacterial activity to be used in patients having MDR and XDR Typhoid.

Gram-negative organisms cause bloodstream infections, pneumonia, meningitis, and surgical site infections (SSI) in the healthcare setup. These organisms have the ability to transfer genetic material that can make other bacteria resistant to antimicrobials. They also find novel ways to be resistant to antimicrobials due to their built-in abilities. In most of the infections caused by Gramnegative organisms, the therapeutic options have become limited to a critical level. Most of the new antimicrobial agents are in the planning stage, and a considerably good potential remains unexplored in this regard. ${ }^{13}$ This study aims at evaluating the in vitro antibacterial activity of MGO against the blood culture isolates of S. Typhi and various other Gram negative rods.

\section{METHODS}

It was an experimental study conducted at the Department of Microbiology, University of Health Sciences (UHS), Lahore-Pakistan in collaboration with the Department of Microbiology, $\mathrm{CMH}$ Lahore, from July 2011 to June 2012. Microbiological procedures were carried as per recent CLSI guidelines having relevant positive and negative controls. Recently isolated $157 \mathrm{~S}$. Typhi and $33 \mathrm{Gram}$ negative rods from specimens of blood culture were collected from various hospitals of Lahore and were stored at $-80^{\circ} \mathrm{C}$. After thawing and sub-culturing on recommended culture media, Gram stain was done and colony morphology was observed to identify the isolates on preliminary basis. Catalase and oxidase enzymes production were tested and motility was observed by hanging drop method. API-20 E (bioMerieux, France) panels were used to perform biochemical identification. $\mathrm{O}, \mathrm{H}$ and Vi (BD Difco, USA) polyvalent and group specific Salmonella antisera were used to identify them serologically. Disc diffusion method (Kirby-Bauer) was used to carry out antimicrobial susceptibility testing of the isolates on Meuller-Hinton agar (MHA)

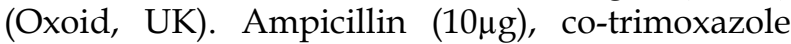
$(1.25 / 23.75 \mu \mathrm{g})$, chloramphenicol $(30 \mu \mathrm{g})$, nalidixic acid $(30 \mu \mathrm{g})$, ciprofloxacin $(5 \mu \mathrm{g})$, ceftriaxone $(30 \mu \mathrm{g})$, aztreonam $(15 \mu \mathrm{g})$ and imipenem $(10 \mu \mathrm{g})$, antibiotic discs (Oxoid, Basingstoke, UK) were applied with their respective disc contents and zones of inhibition 
were noted in millimeters $(\mathrm{mm})$ after incubation at $35^{\circ} \mathrm{C}$ aerobically for $18-24$ hours. MP Pharma (29525 Fountain Parkway Solon, OH 44139, USA) was the authorized supplier from where MGO was purchased. Its expiry and sterility were confirmed before use. MGO was tested for its MICs by agar dilution method against 157 blood culture isolates of S. Typhi, 33 Gram negative rods and 6 ATCC (American Type Culture Collection) control stains. For inoculating multiple isolates simultaneously, multi-point inoculator (Mast Diagnostics, England) was used. For incorporation into the MHA, serial dilutions of MGO were made from $0.08 \mathrm{mg} / \mathrm{mL}$ to $0.24 \mathrm{mg} / \mathrm{mL}$, based on its molecular weight 76.02 and these plates were incubated aerobically at $35^{\circ} \mathrm{C}$ for 18-24 hours. ATCC control strains were used to monitor the study as positive control strains and indigenous Gram negative organisms were also used to compare and validate this experimental work. ${ }^{14}$

The tested GNR isolates $(n=33)$ include Escherichia coli $(n=18)$, Klebsiella pneumoniae $(n=6)$, Enterobacter cloacae $(n=2)$, Klebsiella oxytoca $(n=2)$, Citrobacter braakii $(n=2)$, Enterobacter agglomerans $(n=2)$ and Enterobacter aerogenes $(n=1)$. The ATCC control strains $(n=6)$ used were Staphylococcus aureus ATCC-25923 $(n=1)$, Escherichia coli ATCC$25922(n=1)$, Klebsiella pneumoniae ATCC-700721 $(n=1)$, Salmonella typhimurium ATCC-39183 $(n=1)$, Acinetobacter baumanii ATCC-19606 $(n=1)$ and Klebsiella oxytoca ATCC-700324 $(n=1)$. For internal quality control three MHA plates were used. First one contained MHA with MGO incorporated in it, second plate had MHA with incorporated MGO but inoculated with sterile pins of the multi-inoculator, and the third plate contained MHA without MGO but inoculated by pins of the multi-inoculator impregnated with the test and control isolates. When observed with an unaided eye and against a dark background, the MIC was determined as the least concentration of MGO at which there was no bacterial growth visible on surface of the agar.

The data was interpreted according to defined criteria of MIC range, $\mathrm{MIC}_{50}$ and $\mathrm{MIC}_{90}$. The data was further sorted out by SPSS v.22. Independent

Table-I: MICs of MGO against S. Typhi (n=157).

\begin{tabular}{|c|c|c|c|c|}
\hline & \multicolumn{3}{|c|}{ MICs of MGO } & Mean $\pm S D$ \\
\hline & Range & $M I C_{50}$ & $M I C_{90}$ & \\
\hline In $\mathrm{mg} / \mathrm{mL}$ & 0.14 to 0.24 & 0.19 & 0.20 & 0.05 \\
\hline In $\mathrm{mM}$ & 2.0 to 3.4 & 2.7 & 2.8 & 0.7 \\
\hline
\end{tabular}

sample t-test was applied to see the difference in antibacterial activity of MGO among all groups of isolates independently. The results were considered to be statistically significant at $\mathrm{p}$-value $<0.05$.

\section{RESULTS}

The first two internal control plates did not show any growth but the third one showed growth of all organisms. All ATCC control strains also showed growth. A total of $157 \mathrm{~S}$. Typhi and 33 Gram negative rods isolates were tested against a panel of antibiotics. The range of MICs of MGO against S. Typhi group was 0.14 to $0.24 \mathrm{mg} / \mathrm{mL}$ (2.0 to 3.4 $m M)$, while it was slightly narrower 0.16 to 0.22 $m g / m L(2.3$ to $3.1 m M)$ against Gram negative rods group. The $\mathrm{MIC}_{90}$ of MGO against $\mathrm{S}$. Typhi group was $0.20 \mathrm{mg} / \mathrm{mL}(2.8 \mathrm{mM})$, while it was slightly higher against Gram negative rods group $0.21 \mathrm{mg} /$ $m L(3.0 \mathrm{mM})$ (Tables-I and II).The Mean \pm SD of S. Typhi group was $0.05 \mathrm{mg} / \mathrm{mL}(0.7 \mathrm{mM})$, whereas, the Mean \pm SD of GNR group was $0.03 \mathrm{mg} / \mathrm{mL}(0.4 \mathrm{mM})$. Independent sample t-test showed that the p-value of MICs of MGO against S. Typhi group when compared to other Gram negative rods group was 0.023 ( $p<0.05$; statistically significant), with Mean \pm SD $0.04 \pm 0.02$.

\section{DISCUSSION}

Based on MIC and MBC, it has been demonstrated that honey and its components show a superb antimicrobial action against $S$. aureus, E. faecalis, $P$. aeruginosa, E. coli, and many other clinical pathogens including fungal isolates in combating infections due to these microorganisms in hospital practice. ${ }^{15}$ Increased virulence in S. Typhi may be due to the presence of other virulence genes on R-plasmid. In Pakistan, high mortality and severe complicated illnesses have been reported due to circulating strains of MDR and XDR S. Typhi. ${ }^{16}$

In this study, the $\mathrm{MIC}_{90}$ of $\mathrm{MGO}$ against $\mathrm{S}$. Typhi isolates was $0.20 \mathrm{mg} / \mathrm{mL}(2.8 \mathrm{mM})$, and GNR isolates having E. coli strains $(n=18)$ was $0.21 \mathrm{mg} / \mathrm{mL}(3.0 \mathrm{mM})$ and control strains of $E$. coli ATCC 25922 was $0.20 \mathrm{mg} / \mathrm{mL}(2.8 \mathrm{mM})$ and

Table-II: MICs of MGO against other GNR Isolates $(n=33)$.

\begin{tabular}{|c|c|c|c|c|}
\hline & \multicolumn{3}{|c|}{ MICs of MGO } & $M e a n \pm S D$ \\
\hline & Range & $M_{I C}$ & $M I C_{90}$ & \\
\hline In mg/mL & 0.16 to 0.22 & 0.20 & 0.21 & 0.03 \\
\hline In $\mathrm{mM}$ & 2.3 to 3.1 & 2.8 & 3.0 & 0.4 \\
\hline
\end{tabular}


S. aureus ATCC 25923 was $0.15 \mathrm{mg} / \mathrm{mL}(2.2 \mathrm{mM})$. These values are relatively but proportionately high when compared to a study on MGO, where E. coli and S. aureus had comparatively lower MIC of $0.08 \mathrm{mg} / \mathrm{mL}(1.1 \mathrm{mM})$, as analyzed using the agar well diffusion assay. The studied samples of manuka honey showed antibacterial activity in MGO concentrations of 1.1 to $1.8 \mathrm{mM}$ which corresponded when it was diluted to 15 to $30 \%$, whereas most of the other investigated honeys showed no antibacterial effect in dilutions of up to $80 \%$ (v/v with water) or below. This study also validated that $\mathrm{MGO}$ is unambiguously the predominant non-peroxide antibacterial agent in manuka honey. ${ }^{17}$ Method used for MIC determination in this study was agar dilution, which likely caused the comparative difference. Agar well diffusion method for determination of MIC used by Mavric et al. lacks sensitivity and proper standardization as compared to the agar dilution method, thus affecting the outcome of assay. ${ }^{17,18} \mathrm{MGO}$, a phytochemical compound was inducted in a hydrogel for its topical antibacterial action. Their MICs against $S$. aureus and methicillin-resistant S. epidermis (MRSE) were found comparatively lower $0.07 \mathrm{mg} / \mathrm{mL}$ $(1.05 \mathrm{mM})$. Thus a stable and active combination was prepared which was appropriate for the prophylaxis and treatment of surgical wounds and burns. The $\mathrm{MIC}_{90}$ values $0.20 \mathrm{mg} / \mathrm{mL}(2.8 \mathrm{mM})$ in this study were comparable with a variation towards higher side, but broth dilution assay had been used for determination of MIC. Moreover, in this study the isolates belonged to different genera. MGO showed comparable MIC of 0.15 $\mathrm{mg} / \mathrm{mL}(2.2 \mathrm{mM})$ against S. aureus ATCC 25923 which was used as a control isolate in this study. ${ }^{19}$ Taking a lead, many researchers impregnated the substrate of non-woven wound dressings with manuka honey or MGO. To facilitate a good antimicrobial effect against $S$. aureus and $K$. pneumoniae, the range of MGO concentration required was 0.0170 to $0.1 \mathrm{mg} / \mathrm{cm}^{2}$. Against the three prevalent wound and nosocomial pathogens, i.e., S. aureus, $P$. aeruginosa and E. faecalis, the liquid form MIC and MBC were also evaluated for MGO.

In order to achieve a good bacteriostatic or bactericidal effect in materials other than the MGO-impregnated fabrics, the solutions with comparatively much higher MGO concentrations in the range of $128 \mathrm{mg} / \mathrm{L}$ to $1024 \mathrm{mg} / \mathrm{L}$ were required. The importance of the MGO-based impregnation as environmental friendly and antibiotic-free wound dressings was proved scientifically by comparison. ${ }^{20}$

The range of MIC of MGO against S. Typhi in this study was 0.16 to $0.22 \mathrm{mg} / \mathrm{mL}$ (2.3 to $3.1 \mathrm{mM}$ ), it is however comparable to an effective concentration (EC) range of MGO against a Gram negative rod P. aeruginosa was 0.15 to $1.2 \mathrm{mg} / \mathrm{mL}$ (2.1 to 16.4 $m M$ ), and against $S$. aureus was 0.08 to $0.3 \mathrm{mg} /$ $\mathrm{mL}$ (1.1 to $4.3 \mathrm{mM}$ ). EC against sessile (biofilmforming) $P$. aeruginosa ranged from 0.5 to $3.6 \mathrm{mg} /$ $m L$. S. aureus and $P$. aeruginosa are the known organisms that cause formation of polysaccharide biofilms on implanted devices or tissues in postsurgical patients. Biofilms render the antibiotics impenetrable, thus leading to therapeutic failure. MGO is a potent antibacterial agent against both the planktonic and sessile (biofilmforming) organisms. ${ }^{21}$ Under non-physiologic conditions, the results of some of the MGO invitro experiments have been extrapolated to the in-vivo conditions, but with varied and confusing conclusions. However, the overall potential beneficial effects of MGO clearly outweigh its possible toxic role in in vivo conditions, meriting it to be utilized cautiously for the benefit of ailing humanity at this stage. ${ }^{22}$ However, the potential topical and systemic safety profile of MGO needs to be established in order for it to be used as a prospective antibacterial agent.

\section{CONCLUSION}

MGO has been observed to have a scientifically proven in vitro antibacterial activity against blood culture isolates of S. Typhi and various genera of Gram negative rods.

Grant Support \& Financial Disclosures: None.

\section{REFERENCES}

1. Molan PC. The role of honey in the management of wounds. J Wound Care. 1999;8(8):415-418. doi: 10.12968/ jowc.1999.8.8.25904.

2. Cokcetin NN, Pappalardo M, Campbell LT, Brooks P, Carter DA, Blair SE, et al. The antibacterial activity of Australian Leptospermum honey correlates with methylglyoxal levels. PloS One. 2016;11(12):e0167780. doi: 10.1371/journal. pone. 0167780 .

3. Karasawa K, Haraya S, Okubo S, Arakawa H. Novel assay of antibacterial components in manuka honey using lucigeninchemiluminescence-HPLC. Anal Chim Acta. 2017;954:151158. doi: 10.1016/j.aca.2016.12.004.

4. Majtan J. Methylglyoxal-a potential risk factor of manuka honey in healing of diabetic ulcers. Evid Based Complement Alternat Med. 2010;2011:Article ID 295494, 5 pages. doi: 10.1093/ecam/neq013. 
5. Grainger MN, Manley-Harris, Lane JR, Field RJ. Kinetics of conversion of dihydroxyacetone to methylglyoxal in New Zealand mānuka honey: Part I--Honey systems. Food Chem. 2016;202:484-491. doi: 10.1016/j. foodchem.2016.02.029.

6. Wallace A, Eady S, Miles M, Martin H, McLachlan A, Rodier $\mathrm{M}$, et al. Demonstrating the safety of manuka honey UMF® 20+ in a human clinical trial with healthy individuals. Br J Nutr. 2010;103(7):1023-1028. doi:10.1017/ S0007114509992777.

7. Rabbani N, Xue M, Thornalley PJ. Methylglyoxalinduced dicarbonyl stress in aging and disease: first steps towards glyoxalase 1-based treatments. Clin Sci (Lond). 2016;130(19):1677-1696. doi: 10.1042/CS20160025.

8. Hayes G, Wright N, Gardner SL, Telzrow CL, Wommack AJ, Vigueira PA. Manuka honey and methylglyoxal increase the sensitivity of Staphylococcus aureus to linezolid. Lett Appl Microbiol. 2018;66(6):491-495. doi: 10.1111/lam.12880.

9. Lu J, Turnbull L, Burke CM, Liu M, Carter DA, Schlothauer RC, et al. Manuka-type honeys can eradicate biofilms produced by Staphylococcus aureus strains with different biofilm-forming abilities. Peer J. 2014;2:e326. doi: $10.7717 /$ peerj.326.

10. Radhakrishnan A, Als D, Mintz ED, Crump JA, Stanaway $\mathrm{J}$, Breiman RF, et al. Introductory article on global burden and epidemiology of typhoid fever. Am J Trop Med Hyg. 2018;99(3_Suppl):4-9. doi: 10.4269/ajtmh.18-0032.

11. Levine MM, Simon R. The Gathering Storm: Is Untreatable Typhoid Fever on the Way? MBio. 2018;9(2):e00482-18. doi: 10.1128/mBio.00482-18

12. Klemm EJ, ShakoorS, Page AJ, Qamar FN, Judge K, Saeed DK, et al. Emergence of an extensively drug-resistant Salmonella enterica serovar Typhi clone harboring a promiscuous plasmid encoding resistance to fluoroquinolones and thirdgeneration cephalosporins. MBio. 2018;7:9(1):e00105-18. doi: 10.1128/mBio.00105-18.

13. Bonomo RA, Hooper DC, Kaye KS, Johnson JR, Clancy CJ, Thaden JT, et al. Gram-negative bacterial infections: research priorities, accomplishments, and future directions of the Antibacterial Resistance Leadership Group. Clin Infect Dis. 2017;64(suppl_1):S30-35. doi: 10.1093/cid/ciw829.

14. Hannan A. In vitro activity of ofloxacin against 210 clinical isolates of typhoid salmonellae. Infection. 1986;14(4):S243-S244. doi: 10.1007/BF01661282.

15. Huttunen S, Riihinen K, Kauhanen J, Tikkanen-Kaukanen C. Antimicrobial activity of different Finnish monofloral honeys against human pathogenic bacteria. APMIS. 2013;121(9):827-834. doi: 10.1111/apm.12039.
16. Andrews JR, Qamar FN, Charles RC, Ryan ET. Extensively Drug-Resistant Typhoid - Are Conjugate Vaccines Arriving Just in Time? N Engl J Med. 2018;379:1493-1495. doi: 10.1056/NEJMp1803926.

17. Mavric E, Wittmann S, Barth G, Henle T. Identification and quantification of methylglyoxal as the dominant antibacterial constituent of Manuka (Leptospermum scoparium) honeys from New Zealand. Mol Nutr Food Res. 2008;52(4):483-489. doi: $10.1002 /$ mnfr.200700282.

18. Lusby PE, Coombes AL, Wilkinson JM. Bactericidal activity of different honeys against pathogenic bacteria. Arch Med Res. 2005;36(5):464-467. doi: 10.1016/j.arcmed.2005.03.038.

19. Fidaleo M, Zuorro A, Lavecchia R. Methylglyoxal: a new weapon against staphylococcal wound infections? Chem Lett. 2010;39(4):322-323. doi: 10.1246/cl.2010.322.

20. Bulman SE, Tronci G, Goswami P, Carr C, Russell SJ. Antibacterial Properties of Nonwoven Wound Dressings Coated with Manuka Honey or Methylglyoxal. Materials (Basel). 2017;10(8):954. doi:10.3390/ma10080954.

21. Kilty SJ, Duval M, Chan FT, Ferris W, Slinger R. Methylglyoxal: (active agent of manuka honey) in vitro activity against bacterial biofilms. Int Forum Allergy Rhinol. 2011;1(5):348-350. doi: 10.1002/alr.20073.

22. Talukdar D, Chaudhuri BS, Ray M, Ray S. Critical evaluation of toxic versus beneficial effects of methylglyoxal. Biochemistry (Moscow). 2009;74(10):10591069. doi: $10.1134 /$ S0006297909100010.

\section{Authors' Contribution:}

RKA: conception, literature searchstudy design, questionnaire design, acquisition of data, data collection, study performance, gathering of results, their interpretation and analysis. Drafting, editing, finalizing, agreed to be accountable for all aspects of the work.

FK: study design, data collection, performance, results, their analysis and interpretation, drafting and finalizing, agreed to be accountable.

AH and SAA: Conception, literature search, study design, interpretation of data, final approval of draft, agreed to be accountable. 